\title{
Correction to: Impact of safety warnings for fluoroquinolones on prescribing behaviour. Results of a cohort study with outpatient routine data
}

\author{
Ulrike Georgi ${ }^{1,2}$ (D) Falko Tesch ${ }^{2}$ (D) Jochen Schmitt ${ }^{2}$ (D) Katja de With
}

Published online: 17 May 2021

(c) The Author(s) 2021

\section{Correction to: Infection \\ https://doi.org/10.1007/s15010-020-01549-7}

The original version of this article unfortunately contained a mistake. The presentation of Fig. 2 was incorrect. The corrected Fig. 2 is given below.

The original article has been corrected.

Open Access This article is licensed under a Creative Commons Attribution 4.0 International License, which permits use, sharing, adaptation, distribution and reproduction in any medium or format, as long as you give appropriate credit to the original author(s) and the source, provide a link to the Creative Commons licence, and indicate if changes were made. The images or other third party material in this article are included in the article's Creative Commons licence, unless indicated otherwise in a credit line to the material. If material is not included in the article's Creative Commons licence and your intended use is not permitted by statutory regulation or exceeds the permitted use, you will need to obtain permission directly from the copyright holder. To view a copy of this licence, visit http://creativecommons.org/licenses/by/4.0/.

The original article can be found online at https://doi.org/10.1007/ s15010-020-01549-7.

Ulrike Georgi

u.georgi@skc.de

1 Pharmacy Service of Clinical Center, Flemmingstrasse 2, 09116 Chemnitz, Germany

2 Center for Evidence-Based Healthcare, University Hospital and Medical Faculty Carl Gustav Carus, TU Dresden, Dresden, Germany

3 Division of Infectious Diseases, University Hospital Carl Gustav Carus, TU Dresden, Dresden, Germany 


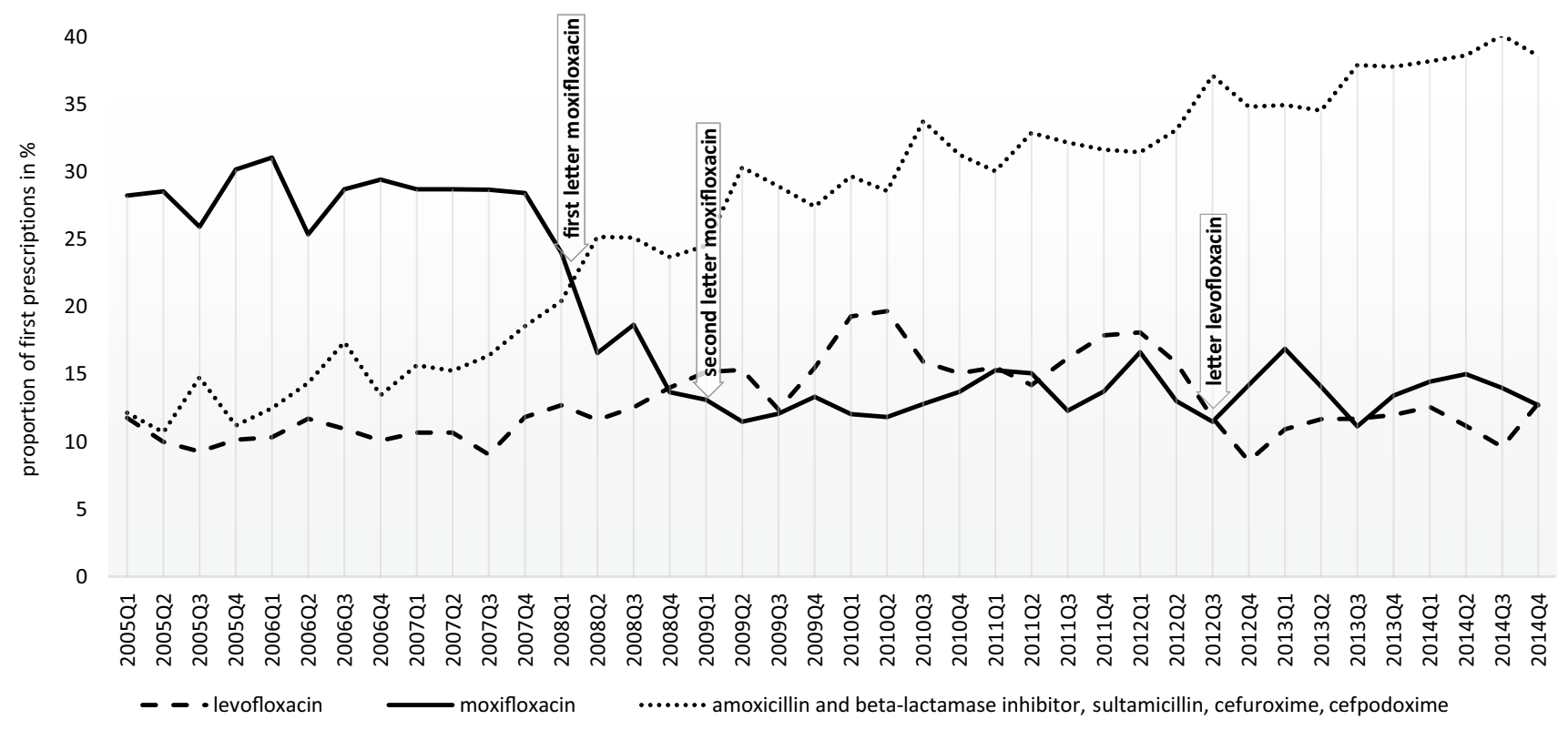

Fig. 2 First prescriptions dispensed for diagnosed CAP in the time period from 2005 to 2014 including the published Dear Doctor Letters (moxifloxacin [02/2008, 01/2009], levofloxacin [09/2012]). Data source-AOK PLUS Saxony 